\title{
International Primary Care Respiratory Group (IPCRG) Guidelines: Management of Chronic Obstructive Pulmonary Disease (COPD)
}

\author{
David Bellamy ${ }^{a, *}$, Jacques Bouchard ${ }^{b}$, Svein Henrichsen ${ }^{c}$, \\ Gunnar Johansson $^{d}$, Arnulf Langhammer ${ }^{\mathrm{e}}$, Jim Reid ${ }^{\mathrm{f}}$, \\ Chris van Weel's, Sonia Buist ${ }^{h}$
}

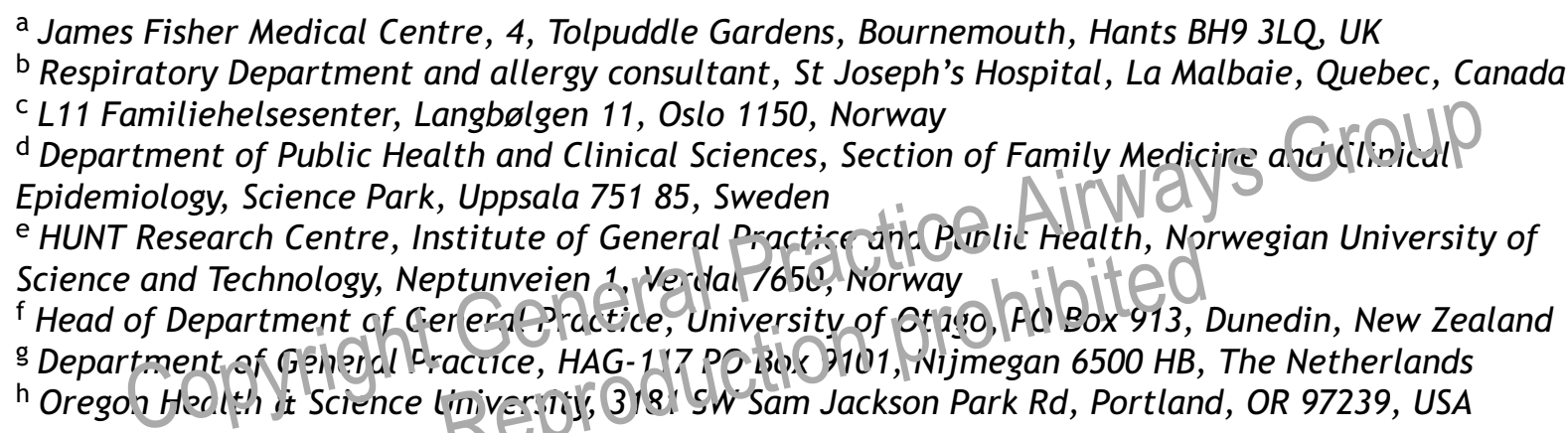

Received 31 October 2005; accepted 9 November 2005

KEYWORDS

Guideline;

Primary care;

General practice;

COPD;

Spirometry;

Classification;

Management;

Treatment

\begin{abstract}
Summary COPD is a common and under-diagnosed disease which is increasing in prevalence worldwide. A more aggressive and optimistic approach must be adopted towards its management in primary care. This IPCRG Guideline on the management of COPD in primary care is fully consistent with GOLD guidelines. It highlights the goals of COPD treatment and the need for spirometric testing to make the diagnosis. It covers the classification of the disease according to disease severity, non-pharmacologic therapy including smoking cessation, avoidance of risk factors, patient education, pharmacologic therapy including the use of oxygen treatment, the management of exacerbations, the role of pulmonary rehabilitation, and the need for monitoring and ongoing care for COPD patients.

(c) 2005 General Practice Airways Group. Published by Elsevier Ltd. All rights reserved.
\end{abstract}

\footnotetext{
* Corresponding author. Tel.: +44 (0)1202 522622;

fax: +44 (0)1202 548580 .

E-mail address: david.bellamy@virgin.net (D. Bellamy).
}

\section{Background}

Primary care physicians treat the majority of patients with respiratory diseases. However, in 
most countries, specific primary care guidelines are not available. Since clinical management which follows evidence-based guidelines yields better results for patients, it is important to have access to primary care guidelines which are specifically relevant to, and provided by, primary care. The International Primary Care Respiratory Group (IPCRG) asked primary care experts from several countries to develop primary care guidelines for the diagnosis and treatment of asthma, chronic obstructive pulmonary disease (COPD) and rhinitis. A brief summary of the expert report (which took three years to complete) was published as a handbook [1] in 2005.

This paper is devoted to the management of COPD and is specifically written for primary care health professionals. It is consistent with the Global Initiative for Chronic Obstructive Lung Disease (GOLD) guidelines [2], which we recommend should be consulted if a more detailed perspective is required. In addition to this section on COPD, the IPCRG guidelines consist of papers on the diagnosis of chronic respiratory diseases in primary care [3], and the management of asthma [4] and rhinitis [5]. For the specific purpose of ranking the evidence in each of these publications, we have used the so-called Three Star System of the Royal College of General Practitioners [6] in order to score tile evidence of the statements made (see tox)? lack of understanding about modern management, is a major hurdle to providing patients with the symptomatic relief and help that they need. A much more aggressive and optimistic approach must be adopted, since there is clear evidence that the various treatments available improve patients in a variety of ways, albeit that they are unable to cure the disease. Breathlessness can be lessened, exercise levels and quality of life improved, and the frequency of acute exacerbations decreased. However, stopping smoking is the only action that will slow the rate of disease progression.

The most important primary care objective should be to improve quality of life. Every effort should be made to reduce exacerbations since a high frequency of exacerbations has been associated with a poorer quality of life and more rapid decline in lung function.

\section{Treatment goals}

While disease prevention is the ultimate goal, once COPD has been diagnosed, effective management should be aimed at the following goals:

- Prevent dicease progrejsion

- Relicve sy miprion

- Inpiove exercise tolsrance

- Improve rea'tin status

Three Sta: System of the noyaic o lege di General Practitioners:

\begin{tabular}{|c|c|}
\hline Evidence Base & $\begin{array}{l}\text { Royal College of General Practitioners. The development and implementation of } \\
\text { clinical guidelines. Report of the clinical guidelines working group. London, 1995, } \\
\text { RCGP [6]. }\end{array}$ \\
\hline *** Strong evidence & Provided by generally consistent findings in multiple, high quality scientific studies. \\
\hline${ }^{* *}$ Moderate evidence & $\begin{array}{l}\text { Provided by generally consistent findings in fewer, smaller or lower quality scientific } \\
\text { studies. }\end{array}$ \\
\hline $\begin{array}{l}\text { " Limited evidence } \\
\text { - No scientific evidence }\end{array}$ & $\begin{array}{l}\text { Provided by one scientific study or inconsistent findings in multiple scientific studies. } \\
\text { Based on clinical studies, theoretical considerations and/or clinical consensus. }\end{array}$ \\
\hline
\end{tabular}

\section{Introduction}

COPD is a common and under-diagnosed disease which is increasing in prevalence worldwide. The disease causes persistent and progressive symptoms which can have major effects on the quality of life of the sufferer, and constitutes a heavy health and economic burden on nation states.

Sadly, despite the prevalence and seriousness of COPD, there is a widely-held view that little can be done to treat the disease other than to stop patients from smoking. This negative attitude, linked to a
- Prevent and treat complications

- Prevent and treat exacerbations

- Reduce mortality.

The aim should be to reach these goals with minimal side effects from treatment and at an affordable cost.

\section{Classification of severity (derived from the GOLD guidelines [2])}

COPD is classified as mild, moderate, severe, or very severe, based on the patient's symptoms, and 
Table 1 Classification of severity of COPD

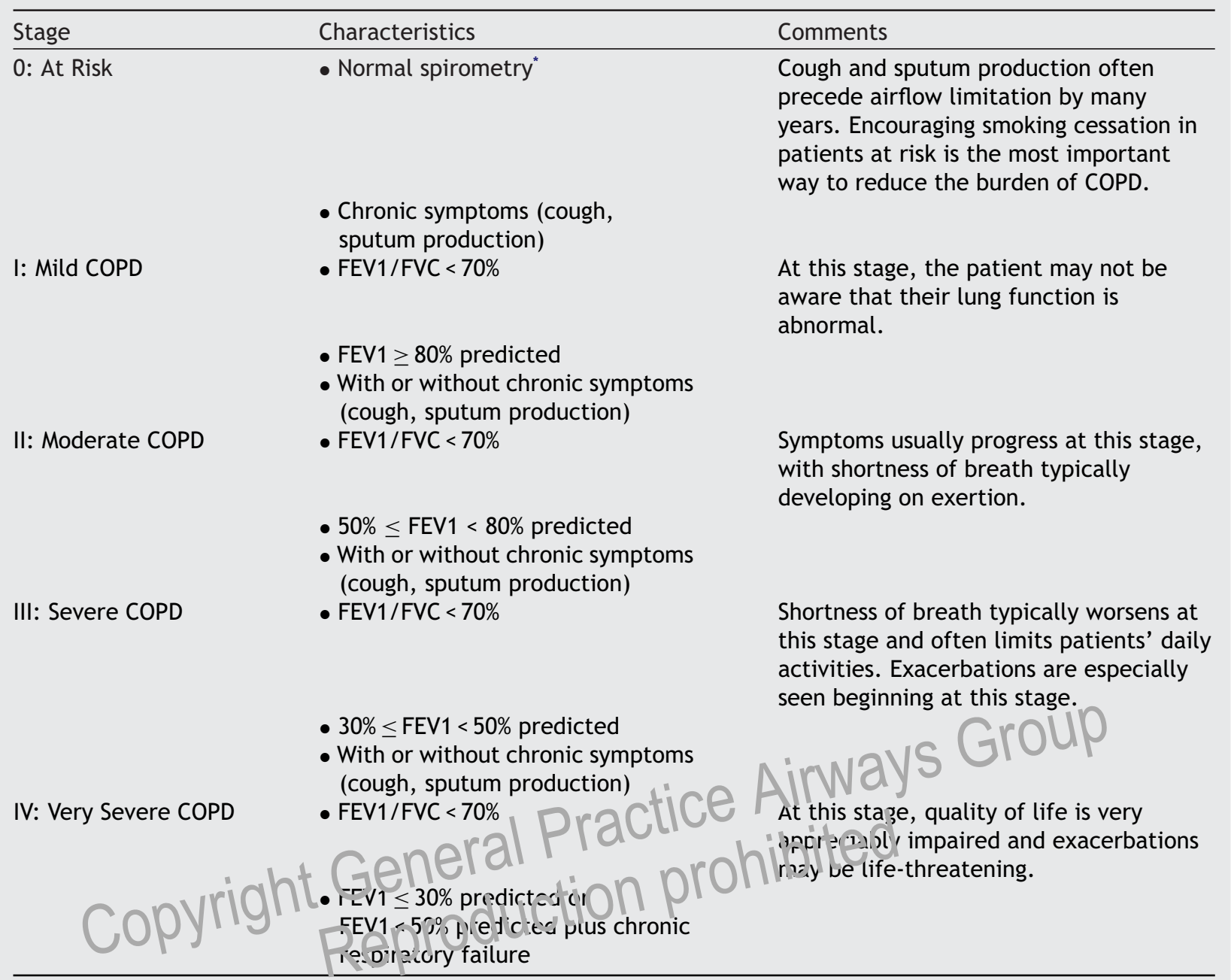

* NOTE: All lung function measurements are post-bronchodilator values.

lung function as assessed by measurement of forced expiratory volume in 1 second (FEV1) and forced vital capacity (FVC) (Table 1). Chronic cough and sputum production often precede the development of airflow limitation by many years, and therefore attention should be paid to patients who have these symptoms and are "at risk" of COPD, but who do not yet have abnormal lung function. Note, however, that not all individuals with cough and sputum production will go on to develop COPD. The severity of COPD will determine the treatment required.

\section{Non-pharmacologic therapy}

Non-pharmacologic therapy is extremely important in COPD because it includes the only treatment -smoking cessation - that can prevent the development and progression of the disease. Patient education and exercise training are also important, as is pulmonary rehabilitation, which can significantly improve health-related quality of life in many patients.

\section{Smoking cessation}

Stopping smoking is the only intervention that will slow the rate of progression of COPD and prolong life expectancy [7] $]^{* * *}$. It will reduce the rate of decline in lung function to that of a nonsmoker in most patients who stop smoking. Smoking cessation is also the single most effective action to reduce the risk of developing COPD [8-10]. Details of evidence-based smoking cessation methods are provided in Appendix A. The need for reduction of exposure to passive or secondhand smoke should also be emphasised to COPD patients.

\section{Avoidance of other risk factors}

\section{Occupational exposure}

Emphasise primary prevention, which is best achieved by elimination or reduction of exposure 
to the various occupational dusts and chemicals that can cause $\mathrm{COPD}^{* *}$. Occupations posing the greatest risk for COPD are linked to exposure to particulate matter such as coalmining. Coal dust alone in sufficient doses can produce airflow limitation. Secondary prevention, achieved through surveillance and early detection, is also important.

\section{Indoor and outdoor air pollution}

Encourage measures to reduce or avoid indoor air pollution from biomass fuel, which is often used in developing countries for cooking and heating. Improving ventilation in homes, using stoves that are more efficient and clean than biofuels, and substituting cleaner fuel, are the most practical solutions to this problem [11].

Advise patients who live in larger cities or areas of significant outdoor air pollution to monitor public announcements of air quality, and, depending on the severity of their disease, to avoid vigorous exercise outdoors or stay indoors altogether during pollution episodes.

\section{Patient education}

Education of COPD patients and caregivel's is an essential part of good disease monagenent $[12,13]^{* * *}$. Individualized tautca ich should be given on an ongoin $b$ as is: at patient visits.

Topics tor educacion include: e pl

- Reducing exposure to risk factors, including tobacco smoke

- Diet-advice on weight gain where the BMI is below 20 since this increases risk of death, or weight reduction to improve mobility

- Importance of regular exercise and maintenance of cardiovascular conditioning

- Correct use of medication

- Recognizing and treating depression

- Management of exacerbations, ideally with a written action plan

- End-of-life issues, coping with severe dyspnoea, and palliative care

- Recognising and treating co-morbidities.

\section{Rehabilitation}

The goal of pulmonary rehabilitation is to reduce symptoms, improve quality of life, and increase participation in everyday activities [14-17] $]^{* * *}$. Rehabilitation programs should include:
Table 2 What you can do if pulmonary rehabilitation is not available

- Start with a small amount of walking which is easily manageable

- Walk every day

- Pace yourself

- Exercise regularly and set realistic goals

- Seek education by asking advice, and read information leaflets

- Try to exercise all year, even in cold and wet weather

- Try to persevere through difficult periods

- Seek advice on weight, diet and lifestyle.

- Exercise training

- Nutrition counselling

- Education.

The program should contain a minimum of six weeks physical exercise, education, and psychosocial intervention.

Patients at all stages of disease benefit from exercise training programs, with improvements in exercise tolerance and reduction in symptoms of dyspnoea and fatigue. Effective lehabilitation programs can be acoriucted in inpatient, outpatient, N rome settings.

Otliesources are minimal, benefits can still be gained $($ Tatle (7) irom instructing patients io ake regular exercise as appropriate to their environment. It is important to reassure patients that performing exercise to the point of breathlessness is not harmful and will, over time, increase their exercise ability. Lower limb exercises are essential, and patients should be encouraged to walk as far as they can until they are breathless.

\section{Oxygen therapy}

Long-term oxygen therapy (LTOT) administered for more than 15 hours per day to COPD patients with chronic respiratory failure improves survival, exercise capacity, and mental state, and has a beneficial impact on pulmonary arterial pressure, polycythemia (defined as a hematocrit of $>55 \%$ ), exercise capacity, lung mechanics, and mental state $[18,19]^{* * *}$.

Initiate oxygen therapy for patients with 'Very Severe COPD' (Stage IV) if:

- $\mathrm{PaO} 2$ is at or below $7.3 \mathrm{kPa}(55 \mathrm{~mm} \mathrm{Hg})$ or $\mathrm{SaO} 2$ is at or below $88 \%$, with or without hypercapnia; or

- $\mathrm{PaO} 2$ is between $7.3 \mathrm{kPa}(55 \mathrm{~mm} \mathrm{Hg})$ and $8.0 \mathrm{kPa}(60 \mathrm{~mm} \mathrm{Hg})$ or $\mathrm{SaO} 2$ is $89 \%$, if there is evidence of pulmonary hypertension, peripheral 
oedema suggesting congestive heart failure, or polycythemia.

- In primary care, if a pulse oximeter is available, an oxygen saturation ( $\mathrm{SaO} 2)$ of less than $92 \%$ should prompt referral for further investigation of the need for oxygen therapy.

The goal of LTOT is to increase the baseline $\mathrm{PaO} 2$ at rest to at least $8.0 \mathrm{kPa}(60 \mathrm{~mm} \mathrm{Hg})$ at sea level, and/or produce an $\mathrm{SaO} 2$ of at least $90 \%$, which will preserve vital organ function by ensuring adequate delivery of oxygen.

Oxygen may be administered from an oxygen concentrator, liquid oxygen, or cylinders, depending on cost and the facilities available locally. It is important that patients be carefully monitored, particularly to assess adherence with the recommendation to use oxygen for more than 15 hours each day.

There is no convincing evidence that mechanical ventilatory support, including NIPPV, has a role in the routine management of stable COPD. *

\section{Pharmacological therapy}

Although COPD cannot be cured, effective pharmacological therapy can relieve patiencs' symptoms, increase their ibiling iccomplish everydav activitics, creduce the frequency of exacertatiors. arid improve their qualit of 1 ide.

Therapy for COPD does nou Necessarily produce an improvement in FEV1, although small changes may be seen in lung volume measurements such as inspiratory capacity and residual volume, which are markers of lung hyperinflation. However, such tests cannot be performed easily in primary care.
Therefore, additional subjective measures such as questions about symptoms, quality of life, and exercise tolerance, should be used to gauge the effectiveness of treatment.

\section{Treatments available}

Bronchodilators (anticholinergics and beta-2 agonists) are central to symptom management in COPD [20-22] ${ }^{* * *}$. They are given on a regular basis in 'Moderate' to 'Very Severe' disease, (Stages II-IV) or on an as-needed basis at all stages of the disease in order to relieve breathlessness and improve exercise capacity. For regular treatment, long-acting bronchodilators are more effective $[23,24]^{* * *}$ and more convenient than short-acting bronchodilators, although they are more expensive.

Inhaled glucocorticosteroids are recommended in patients with 'Severe' (Stage III) and 'Very Severe' (Stage IV) COPD who have repeated exacerbations (three or more in the last three years) requiring oral corticosteroids or antibiotics. Regular treatment with inhaled glucocorticosteroids reduces the Cirequency of exacerbations and inriroves nealth status in this g.oup ei patients [25]***

\section{Theraph inseverity}

The management of COPD should follow a stepwise approach depending on the severity of the individual patient's disease (Table 3). Treatment should be symptom-driven.

COPD is typically a slowly progressive disease. Therefore, treatment generally needs to be maintained at the same level over long periods of

Table 3 COPD therapy by severity

\begin{tabular}{|c|c|c|}
\hline Stage & Essential & Ideal \\
\hline 0: At Risk & $\begin{array}{l}\text { - Avoidance of risk factors } \\
\text { - Influenza vaccination }\end{array}$ & $\begin{array}{l}\text { - Avoidance of risk factors } \\
\text { - Influenza vaccination }\end{array}$ \\
\hline I: Mild COPD & $\begin{array}{l}\text { - Add short-acting bronchodilator } \\
\text { when needed }\end{array}$ & $\begin{array}{l}\text { - Add short-acting bronchodilator } \\
\text { when needed }\end{array}$ \\
\hline II: Moderate COPD & $\begin{array}{l}\text { - Add regular bronchodilator } \\
\text { treatment }\end{array}$ & $\begin{array}{l}\text { - Add regular treatment with one or } \\
\text { more long-acting bronchodilators } \\
\text { - Add rehabilitation }\end{array}$ \\
\hline III: Severe COPD & & $\begin{array}{l}\text { Add medium-to high-dose inhaled } \\
\text { glucocorticosteroids if repeated } \\
\text { exacerbations }\end{array}$ \\
\hline IV: Very Severe COPD & & $\begin{array}{l}\text { - Add long-term oxygen if chronic } \\
\text { respiratory failure } \\
\text { - Consider surgical referral }\end{array}$ \\
\hline
\end{tabular}

For a detailed table summarising available COPD medications, see page 27 of the IPAG Guide [1] and page 69 of the GOLD Guidelines [2]. 
time and eventually "stepped up"' as the patient's disease becomes more severe.

\section{Inhaler use}

Inhaled medications are preferred in the treatment of COPD because high concentrations of the drug can be delivered directly to the airways, producing potent therapeutic effects with few systemic side effects. However, the wider availability, lower cost, and preference for oral medications in some countries needs to be considered.

\section{Exacerbations}

COPD is often associated with exacerbations of symptoms, particularly as the disease progresses.
Most exacerbations are caused by a viral or bacterial infection of the tracheobronchial tree, and some may be caused by an increase in air pollution $[26-28]^{* *}$. The cause of about one-third of severe exacerbations cannot, at present, be identified. Figure 1 provides an overview of the management of COPD exacerbations.

Every effort should be made to prevent exacerbations, as they greatly contribute to the erosion in quality of life in COPD patients and can create a serious social and economic burden on the patient, carers, and the health care system.

\section{Signs and symptoms of an exacerbation}

Common signs and symptoms of an acute exacerbation of COPD include:

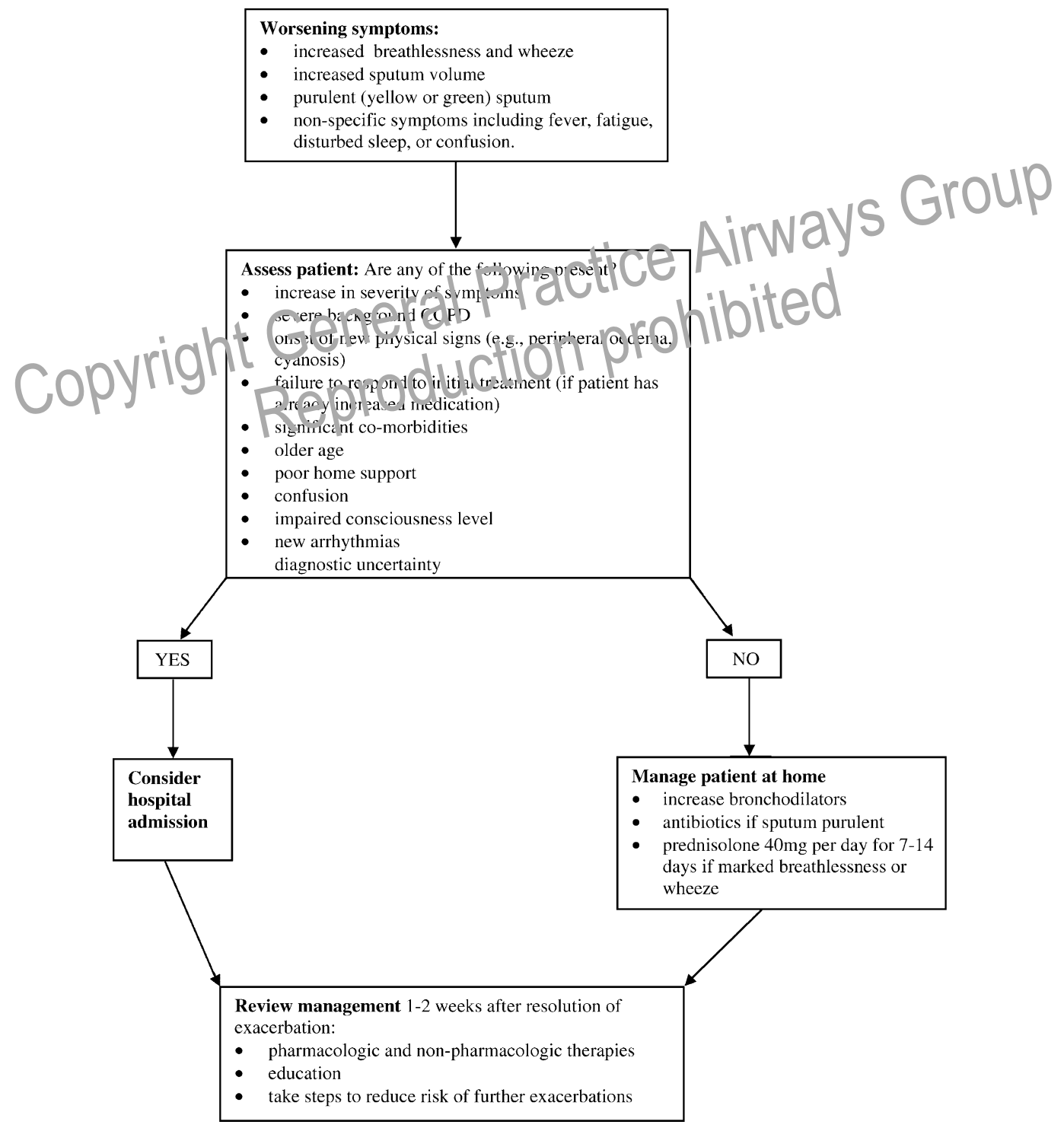

Figure 1 Flow chart for treatment of exacerbations of COPD. 
- Increased breathlessness, wheeze, and chest tightness

- Increased sputum volume

- Increased sputum purulence (white becoming yellow or green; green sputum usually points to a bacterial cause)

- Non-specific symptoms such as fever, malaise, fatigue, sleepiness, and confusion.

\section{Indications for hospital admission}

The risk of dying from an acute exacerbation of COPD is closely related to the development of respiratory acidosis, the presence of serious comorbidities, and the need for ventilatory support. Patients lacking these features are not at high risk of dying, but those with severe underlying COPD often require hospitalization in any case (see Figure 1).

Patients with any of the following characteristics should be considered for hospitalisation, although none of the criteria below are absolute indications for hospitalisation:

- Marked increase in intensity of symptoms, such as sudden development of resting dyspnoea

- 'Severe' (Stage III) or 'Very Severe' (Stage IV) background COPD

- Onset of new physical signs (e.g. edanusis peripheral oedema)

- Failure to respord o intial medical managenér

- Signilicant co-roorbiaities

- Newly occurring arrhythmia.

- Diagnostic uncertainty

- Older age

- Insufficient home support.

\section{Pharmacologic therapy}

\section{Bronchodilators}

Increase dose and/or frequency of existing bronchodilator therapy, or add a bronchodilator of another class (e.g., add an anti-cholinergic if a beta 2 -agonist is already used, or a beta 2 -agonist if an anticholinergic is already used) [29] ${ }^{* * *}$. Higher doses can be administered via a spacer or, for short periods, via nebuliser where available. Both methods can be equally efficacious but when patients are severely dyspnoeic, a nebuliser can be better tolerated.

\section{Oral glucocorticosteroids}

These are used to shorten recovery time, increase the time to the next exacerbation, and improve lung function more quickly [30] $]^{* * *}$. If the patient is more breathless and wheezy, add oral prednisolone 30-40 mg per day for 7-14 days.

\section{Antibiotics}

When symptoms of breathlessness and cough are increased and sputum is purulent and increased in volume, provide antibiotic cover for the major bacterial pathogens involved in exacerbations - Streptococcus pneumoniae, Haemophilus influenzae, Mycoplasma catarrhalis - taking into account local patterns of antibiotic sensitivity $[31,32]^{* *}$. In primary care it is usually necessary to administer antibiotics prior to the results of sputum culture, if sputum culture has been performed.

\section{Follow-up after exacerbations*}

After an exacerbation, the patient should be reviewed periodically until their health status returns to its pre-exacerbation level. The timing and frequency of monitoring should depend on the severity of the exacerbation.

Follow-up after an exacerbation is a good opportunity to review pharmacologic therapy and to consider stepping up treatment or adding rehabilitation, oxygen therapy, or referral to a specialist where appropriate. Smoking cessation should always be re-emphasisled. Prolonged symptoms should lead to sucricion of alternative diagncoes :uch as lung cancer, and require firthe investigation. Attention should also be paid to str.uegles for preventing further exactibations, such as considering the addition of inhaled glucocorticosteroids (see above) to the patient's medication regimen and emphasising the importance of regular influenza vaccination.

\section{Follow-up and on-going care}

\section{Patient monitoring*}

COPD is usually a progressive disease. Lung function can be expected to worsen over time, even with the best available care. Symptoms and lung function should be monitored to follow the development of complications, to guide treatment, and to facilitate discussion of management options. The frequency of monitoring will depend on the health care system and on the individual patient. In general, regular follow-up is needed to:

- Assess the patient's quality of life and whether treatment goals are being met

- Assess the patient's ability to cope with the disease and encourage adherence to the treatment plan

- Review side effects

- Adapt treatment to new advances in therapy. 
Review is also recommended after changes in therapy have been made, to assess compliance, understanding, and side effects. This review should take place within a month of the change in treatment.

\section{Adjusting therapy}

Treatment for COPD is based on symptoms, and therapy will need to be stepped up as the disease progresses and symptoms worsen or complications develop. However, compliance with the current medication regimen should be assessed before stepping up therapy. Therapy may also be adjusted and alternative medication options tried, when side effects or efficacy are unacceptable.

\section{Referral}

Referral to a specialist should be considered if therapy appropriate to the stage of the patient's disease does not control symptoms. Surgical referral for bullectomy or lung transplantation may be considered in carefully selected patients. There is currently insufficient evidence to recommen the widespread use of lung volumereduct: Onl surgery (LVRS).

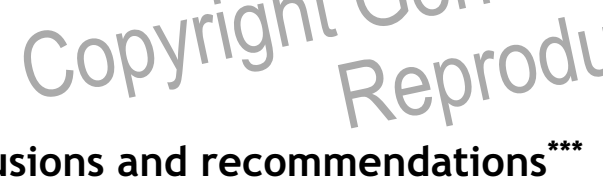

COPD is a common and important disease. Much can be done to prevent the disease and, once established, to slow or minimise further deterioration. A much more positive attitude needs to be adopted regarding the many benefits that treatments can achieve in terms of symptom relief and improving quality of life. COPD is a systemic disease, and a more holistic approach needs to be focused on associated problems such as muscle deconditioning and psychosocial symptoms associated with COPD. The main areas of management can be summarised as;

- Patient education helps in the understanding of the disease process and adherence to therapy

- Stopping smoking is the only intervention that will slow disease progression

- Bronchodilators relieve breathlessness and improve exercise ability

- Inhaled corticosteroids help to reduce the frequency of acute exacerbations
- Pulmonary rehabilitation and regular exercise significantly improves quality of life

- Every effort should be made to reduce exacerbation frequency and to treat exacerbations as promptly as possible

\section{Potential conflicts of interest}

Dr David Bellamy has no shares in pharmaceutical companies. He has received honoraria for speaking at meetings from the following companies: AstraZeneca, GlaxoSmithKline, Altana Pharma, Boehringer Ingelheim and Pfizer. He has also been paid for advisory panel work undertaken for GlaxoSmithKline, Altana Pharma, Boehringer Ingelheim and Pfizer.

Dr Bouchard has no shares in pharmaceutical companies. He has received, as a speaker, honoraria from GSK, MSD and AstraZeneca. He is a temporary member of a scientific advisory board from GSK and MSD.

Dr Svein Hoegh Henrichsen has no shares in pharmaceutical companies. He has received speakers honoraria for speaining at S Sonsored meetings for $A Z, B D, C S K$, MSE Pfizer. He has received hom raria for advisory panel work from GSK and MSD. He hals received honoraria for advisory panell nicik for the Norwegian Directorate for $F \in=(t h)$ and Social Affairs.

Dr Gunnar Johansson has no shares in pharmaceutical companies. He has received speakers honoraria for speaking at sponsored meetings for Astrazeneca, Boehringer-Ingelheim, GSK, MSD and Pfizer. He has received honoraria for advisory panel work from Boehringer-Ingelheim, Pfizer and Astrazeneca.

$\mathrm{Dr}$ A. Langhammer has no shares in pharmaceutical companies or tobacco industry. He has received speakers honoraria for speaking at sponsered meeting for GSK, AZ, MSD, Boehringer Ingelheim. He has received honaria for advisory panel work for AZ, Pfizer and MSD. He was project leader of a substudy of the Nord-Trøndelag Study (HUNT2) focusing on obstructive lung diseases This study was funded by $A Z$ through a contract between the Medical Director of $A Z$ and the Director of the National Institute of Public Health. Dr Langhammer was employed by the National Institute of Public Health during the data collection period.

Associate Professor James J Reid (nor his family) holds no shares in Pharmaceutical Companies. He has received honoraria for advisory work from Astra Zeneca, Glaxo Smith Kline, and Altana. He has received speakers honoraria from Astra Zeneca, GlaxoSmithKline, and Pfizer. 
Professor Chris van Weel has no shares in pharmaceutical companies. He has never personally received an honorarium from the pharmaceutical industry for speaking or advisory panel work. His Department of General Practice, Radboud University Medical Centre, Nijmegen, the Netherlands, has received since 1985, unrestricted research grants from GSK, AZ, Bayer, Boehringer Ingelheim, Novartis, Pfizer and Pharmacia. As the president-elect of the World Organisation of Family Doctors (Wonca) he has been involved in respiratory educational and development activities for which Wonca has been the recipient of unrestricted grants and honoraria from Boehringer Ingelheim and Altana.

Professor A.S. Buist has served on advisory boards for GlaxoSmithKline, ALTANA, Schering Plough and Merck and donates most of her honoraria to the ATS; she has participated in COPD workshops funded by AstraZeneca and GlaxoSmithKline: and is Scientific Director for the Burden of Obstructive Lung Disease (BOLD) an initiative that receives unrestricted educational grants to the Kaiser Permanente Center for Health Research from Boehringer Ingelheim, Pfizer, GlaxoSmithKline, AstraZeneca, Novartis, Chiesi, and Merck.

Funding: During the development of these? guidelines, the IPCRG receive 1] Onrestricted educational grants írpin Litana, AstraZenato Boehringer O'nge'heim, EAMG, Glaxos nithkline, Merck Snarp and Dohme Vivtubisni Pharma, Novartis, UCB Pharma and Zambon. These funds were used for the purpose of funding face-to face-meetings and also to support a secretariat.

\section{Appendix A. Smoking cessation}

Clinicians should enquire about smoking habits during general consultations and offer assistance with cessation wherever appropriate. Details about smoking habit should always be recorded in patient records.

Tobacco dependence is a chronic condition that warrants repeated advice and treatment until longterm or permanent abstinence is achieved. Onethird of smokers have made at least three serious attempts to quit, and surveys in some countries suggest that $70 \%$ of all smokers want to stop smoking.

Even a brief, 3-minute period of counselling to urge a smoker to quit can be effective ${ }^{* * *}$, and at a minimum this should be done for every smoker at every visit [33] (Figure A1-1). More intensive

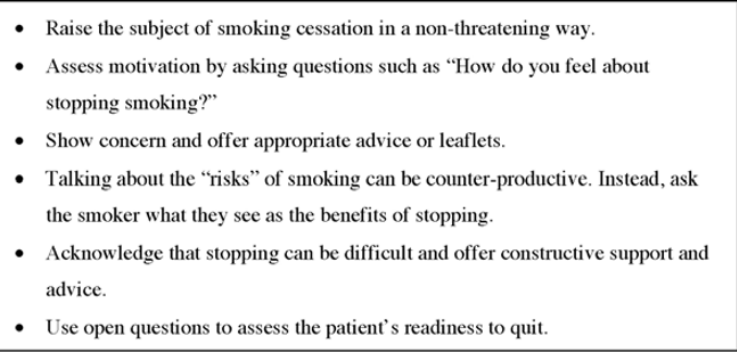

Figure A1 Practical advice for helping patients stop smoking.

group or individual counselling strategies increase the likelihood of sustained quitting ${ }^{* * *}$.

Pharmacotherapy (nicotine replacement and/or buproprion) [34] is recommended when counselling is not sufficient to help patients stop smoking ${ }^{* * *}$. Special consideration should be given before using pharmacotherapy in people smoking fewer than 10 cigarettes per day, pregnant women, adolescents, and those with medical contraindications (unstable coronary artery disease, untreated peptic ulcer, and recent myocardial infarction or stroke for nicotine replacement; a history of / Seizures for buproprion).

Referencies

[1] International Primary Care Airways Group (IPAG). Chronic airways diseases: a guide for primary care physicians. Available at the URL: http://www.ipagguide.org/IPAG_copyright_draft.pdf.

[2] Global Initiative for Chronic Obstructive Lung Disease. Global Strategy for the Diagnosis, Management, and Prevention of Chronic Obstructive Pulmonary Disease. National Institutes of Health, National Heart, Lung, and Blood Institute; April 2001 (Updated 2004). Available at URL: http://www.goldcopd.com.

[3] Levy ML, Fletcher M, Price DB, Hausen T, Halbert RJ, Yawn BP. International Primary Care Respiratory Group (IPCRG) Guidelines: Diagnosis of respiratory diseases in primary care. Prim Care Resp J 2006;15(1):20-34.

[4] van der Molen T, Østrem A, Stallberg B, Stubbe Østergaard $M$, Singh RB. International Primary Care Respiratory Group (IPCRG) Guidelines: Management of asthma. Prim Care Resp J 2006;15(1):35-47.

[5] Price D, Bond C, Bouchard J, Costa R, Keenan J, Levy M, Orru M, Ryan D, Walker S, Watson M. International Primary Care Respiratory Group (IPCRG) Guidelines: Management of allergic rhinitis. Prim Care Resp J 2006;15(1):58-70.

[6] Royal College of General Practitioners. The development and implementation of clinical guidelines. Report of the clinical guidelines working group. London, 1995, RCGP.

[7] Anthonisen NR, Connett JE, Kiley JP, et al. Effects of smoking intervention and the use of an inhaled anticholinergic bronchodilator on the rate of decline of FEV1. The Lung Health Study. JAMA 1994;272:1497-505.

[8] Britton J, Knox A. Helping people to stop smoking: the new smoking cessation guidelines. Thorax 1999;54:1-2. 
[9] The tobacco use and dependence clinical practice guideline panel, staff, and consortium representatives. A clinical practice guideline for treating tobacco use and dependence. JAMA 2000;28:3244-54.

[10] American Medical Association. Guidelines for the diagnosis and treatment of nicotine dependence: how to help patients stop smoking. Washington DC: American Medical Association; 1994.

[11] Smith KR. National burden of disease in India from indoor pollution. Proc Natl Acad Sci USA 2000;97:13286-93.

[12] Janelli LM, Scherer YK, Schmeider LE. Can a pulmonary health teaching program alter patients' ability to cope with COPD? Rehabil Nurs 1991;16:199-202.

[13] Ashikaga T, Vacek PM, Lewis SO. Evaluation of a communitybased education program for individuals with chronic obstructive pulmonary disease. J Rehabil 1980;46:23-7.

[14] Berry MJ, Rejeski WJ, Adair NE, et al. Exercise rehabilitation and chronic obstructive pulmonary disease stage. Am J Respir Crit Care Med 1999;160:1248-53.

[15] Behnke M, Taube C, Kirsten D, et al. Home - based exercise is capable of preserving hospital - based improvements in severe chronic obstructive pulmonary disease. Respir Med 2000;94:1184-91.

[16] Green RH, Singh SJ, Williams J, et al. A randomised controlled trial of four weeks versu seven weeks of pulmonary rehabilitation in chronic obstructive pulmonary disease. Thorax 2001;56:143-5.

[17] Ries AL, Kaplan RM, Myers R, et al. Maintenance after pulmonary rehabilitation in chronic lung disease: a randomised trial. Am J Crit Care Respir Med 2003;167:880-8.

[18] Nocturnal Oxygen Therapy Group. Continuous or nocturnal oxygen therapy in hypoxemic chronic obstructive lung disease: a clinical trial. Ann Intern Med 1980;93:301-8.

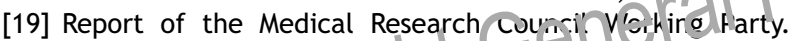
Long term domiciliary oyen the rar y chronic hypoxi cor primonate broplic.ting chronic bronchitis anc emphysema licice: 1981,1:681- 6 .

[20] Vathenen AS, Britton JR, Ebden $F \in t$ al. High dose inhaled albuerol in severe chronic airflow limitation. Am Rev Resp Dis 1988;138:850-5.

[21] Gross NJ, Petty TL, Friedman M, et al. Dose response to ipratropium as a nebulized solution in patients with chronic obstructive pulmonary disease. A three -center study. Am Rev Respir Dis 1989;139:1188-91.
[22] COMBIVENT Inhalation Aerosol Study Hgroup. In chronic obstructive pulmonary disease, a combination of ipratropium and albuterol is more effective than either agent alone. An 85-day multicenter trial. Chest 1994;105:1411-9.

[23] Mahler DA, Donohue JF, Barbee RA, et al. Efficacy of salmeterol xinofoate in the treatment of COPD. Chest 1999;115:957-65.

[24] VinckenW, van Noord JA, Greefhorst AP, et al. Improved health outcomes in patients with COPD during 1 years treatment with tiotropium. Eur Respir J 2002;19:209-16.

[25] Burge PS, Calverley PM, Jones PW, et al. Randomised, double blind, placebo controlled study of fluticasone propionate in patients with moderate to severe chronic obstructive pulmonary disease: the ISOLDE trial. BMJ 2000;320:1297-303.

[26] Gibson PG, Wiodarczyk JH, Wilson AJ, et al. Severe exacerbation of chronic obstructive airways disease: health resource use in general practice and hospital. J Qual Clin Pract 1998;18:125-33.

[27] Wilson R. The role of infection in COPD. Chest 1998;113:242S-8S.

[28] Anderson HR, Spix C, Medina S, et al. Air pollution and daily admissions of chronic obstructive pulmonary disease in 6 European cities: results from the APHEA project. Eur RESPIR j 1997; 10:1064-71.

[29] Lloberes P, Ramis L, Montserrat JM, et al. Effect of three different bronchodilators during an exacerbation of chronic obstructive pulmonary disease. Eur Respir J 1988;1:536-9.

[30] Davies L, Angus RM, Calverley FM. Crit corticcsteroids in patients admitted to hospilativith e ace bations of chronic cbstructive fulincric j cis ase. Lancet 1999;354:456-60.

[31] Al-honisen NR, Manfreda J, Warren CP, et al. Antibiotic therapy in exacerlatio is of chronic obstructive pulmonary diseaso in $n$ interi isa 1987;106:196-204.

[32] Stcckles RA, O'Brien C, Pye A, et al. Relationship of sputum colour to nature and oupatient management of acute exacerbations of COPD. Chest 2000;117:1838-45.

[33] Lancaster T, Steaad L, Silagy C, et al. Effectiveness of interventions to help people stop smoking: findings from the Cochran Library. BMJ 2000;321:355-8.

[34] Fiore MC, Smith SS, Jorenby DE, et al. The effectiveness of the nicotine patch for smoking cessation. A meta-analysis. JAMA 1994;271:1940-7.

Available online at www.sciencedirect.com

science@Direct.

\section{Available online at http://www.thepcrj.com}

